\title{
Grain refinement efficiency of a new oxide-containing master alloy for aluminium casting alloys
}

\author{
V.M. Sreekumar ${ }^{1, a^{*}}$, N. Hari Babu ${ }^{1, b}$, D.G. Eskin ${ }^{1, c}$, Z. Fan ${ }^{1, d}$ \\ ${ }^{1}$ BCAST, Brunel University, UB8 3PH, United Kingdom \\ ${ }^{a}$ Email:Sreekumar.VadakkeMadam@brunel.ac.uk \\ ${ }^{b}$ Email: Hari-Babu.Nadendla@brunel.ac.uk \\ cEmail: Dmitry.Eskin@brunel.ac.uk \\ dEmail: Zhongyun.Fan@brunel.ac.uk
}

Key words: grain refinement, oxide, ultrasonic processing, casting

\begin{abstract}
In this study, grain refinement efficiency of a new oxide-containing master alloy was demonstrated on an A357 alloy. The grain size of the reference alloy was reduced by $50-60 \%$ with the addition of the master alloy and introduction of ultrasonic cavitation. A higher addition of master alloy was found to be not benificial in further reducing the grain size.
\end{abstract}

\section{Introduction}

Grain refinement has been an important technique for improving the quality of aluminium products for many decades. Addition of grain refiners in the form of master alloys containing potent nucleants suppresses the formation of columnar grains and promotes equiaxed structure [1-3]. Finer grain size reduces the casting defects and eventually improves the mechanical properties of the material. For foundry alloys, grain refiners increase the casting properties as well. The grain refinement technique has become a well-established practice in aluminium based wrought and foundry alloys [4]. In industrial practice, $\mathrm{Al}-\mathrm{Ti}-\mathrm{B}$ master alloys are the most commonly used grain refiners in cast and wrought $\mathrm{Al}$ alloys.

There has been numerous studies conducted till date on the development of new grain refiners and their grain refinement charecteristcs in aluminium [1-4]. Also mechanism of grain refinement by Al-Ti-B grain refiners has been explained by various analytical models and theories and verified experimentally [1-7]. It has been realized that peritectics often can effectively refine the grains of $\mathrm{Al}$, e.g. Ti, $\mathrm{V}, \mathrm{Nb}, \mathrm{Zr}$ with $\mathrm{Al}$ [5]. In line with several theories suggested earlier, investigators have obtained experimental evidence that the pro-peritectic $\mathrm{TiAl}_{3}$ phase is formed on $\mathrm{TiB}_{2}$ or $\mathrm{AlB}_{2}$ prior to the nucleation of $\alpha-\mathrm{Al}$, indicating that a $\mathrm{TiAl}_{3}$ phase may be responsible for the enhanced grain refinement in Al-Ti-B system [5,6]. The most successful grain refiners to date are Ti-based compounds ( $\mathrm{TiB}_{2}, \mathrm{TiAl}_{3}$ and $\mathrm{TiC}$ ) [8,9] in $\mathrm{Al}$ alloys and $\mathrm{Zr}$ in $\mathrm{Al} / \mathrm{Mn} / \mathrm{Si}$-free $\mathrm{Mg}$ alloys [5]. Titanium boride-containing master alloys are much less efficient in Al-Si alloys due to the formation ot titanium silicide [1, 2]. Therefore, the search for an efficient grain refiner for Al-Si foundry alloys is an ongoing research topic. In regard to the efficiency of grain refiner, free growth model theoretically demonstrated that undercooling for free growth is inversely proportional to the inoculant particle diameter, and the size distribution of the particles plays an important role in determining the efficiency of a given grain refiner [10].

Oxides are naturally occurring phases on Al surface. These oxides are found to be thermodynamically and crystallographically stable with $\mathrm{Al}$ in different conditions A possibility of utilizing exogeneous and naturally formed oxide particles as nucleating substrates for grain refining Al alloys, especially under condition of external physical field applied, has been reported [14, 11, 12]. Atamanenko et al. showed the grain refining effect of indigenous $\mathrm{Al}_{2} \mathrm{O}_{3}$ in pure $\mathrm{Al}$ by ultrasonic cavitation-induced heterogeneous nucleation through the activation of oxides [11]. 
Further, Li et al demonstrated grain refinement of Al-Mg alloys via dispersing naturally occurring oxides such as $\mathrm{MgAl}_{2} \mathrm{O}_{4}(200-500 \mathrm{~nm})$ in $\mathrm{Al}$ alloys using an intensive melt shearing technique [12].

This paper outlines grain refinement potency of a new oxide-based master alloy in a commecrically important Al alloy, A357. Detailed microstructure charecterization demonstrates the exent of grain refinement in the alloy with different additions of the master alloy and introduction of ultrasonic caviation.

\section{Experiment details}

400 grams of an A357 (Al 91.8, Si 7.2, Mg 0.5, Fe 0.2, Ti 0.1, in wt\%) alloy was superheated above $750{ }^{\circ} \mathrm{C}$ in a graphite crucible inside an electric furnace. Different amounts of oxide-based master alloy $(0.25,1,1.7,4.2,5.8$, in wt $\%)$ were diluted into the molten alloy at the temperature. The alloy was held for 5 min after the addition. In other experiments, ultrasonication $(17.5 \mathrm{kHz}$ frequency, $4 \mathrm{~kW}$ power, $30 \mu \mathrm{m}$ amplitude, $\mathrm{Nb}$ sonotrode) was performed for $2 \mathrm{~min}$ after the addition of master alloy. The alloy was subsequently cast in a metallic cylindrical mould (preheated at $250{ }^{\circ} \mathrm{C}$ ) at $750{ }^{\circ} \mathrm{C}$ to produce $100-\mathrm{mm}$ long and $30 \mathrm{~mm}$ in diameter sample. The samples were selected $20 \mathrm{~mm}$ from the bottom of the cast and polished using OPS solution and anodized using $3 \% \mathrm{HBF}_{4}$ solution. Microstructure charecterizations were carried out using normal and polarized light modes in an optical microscop XXX to reveal microstructure and grain sizes, respectively. The microstructures were taken from identical areas (between $5 \mathrm{~mm}$ from centre and edge of the sample surface) for different samples. Average grain size was calculated (5\% standard deviation) by the linear intercept method using 3 micrographs (10 intercepts) for each sample.

\section{Results}

Figure 1 shows the optical microstructures of the Al-oxide master alloy prepared. Oxide particles were found to be distributed in clusters along the grain boundaries of the alloy. The oxide particles were identified as in-situ $\mathrm{Mg}$ spinel $\left(\mathrm{MgAl}_{2} \mathrm{O}_{4}\right)$ with $100-300 \mathrm{~nm}$ avarage particle size. The amount of spinel particles in the master alloy was estimated as $2 \mathrm{wt} \%$. (Production and other details of the master alloy may not be revealed at this stage).

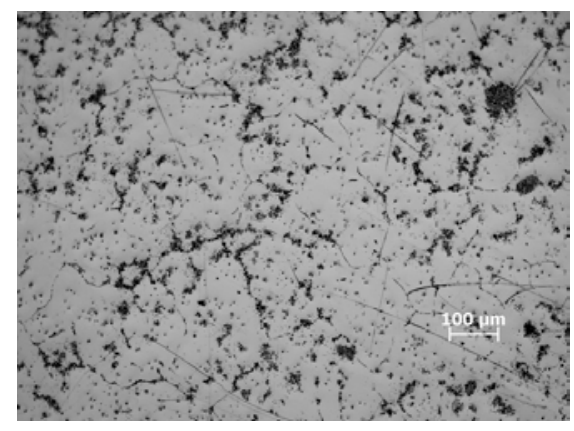

(a)

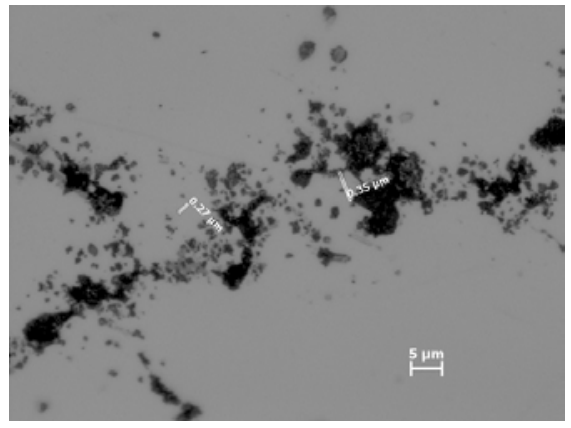

(b)

Fig. 1. Optical microstructure of Al-oxide master alloy (a) and distribution of in-situ Mg spinel particles in the master alloy alloy (b).

Figure 2 compares the grain structure of the A357 alloys without master alloy additions cast without and with ultrasonication. The samples with ultrasonication showed a smaller grain size (G.S.) compared to the reference alloy. A similar observation was made by Atamanenko et al. [11] in $\mathrm{Al}-4 \% \mathrm{Cu}$ alloy, where the grain size was reduced by $20 \%$ in the presence of ultrasonic cavitation. 


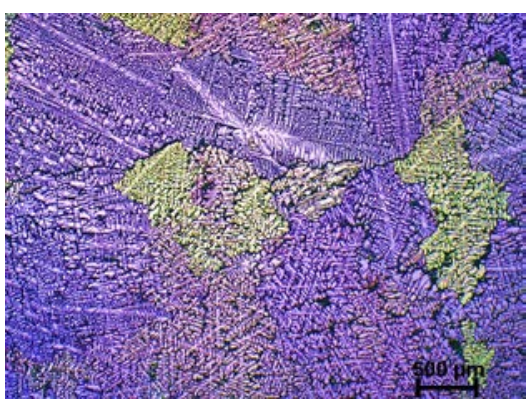

(a)

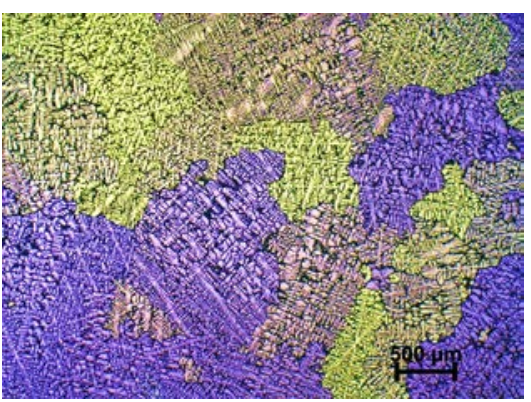

(b)

Fig. 2: Grain structure in an A357 alloy (a) no ultrasonication (Avg G.S. $=900 \mu \mathrm{m}$ ) and (b) with ultrasonication (Avg G.S. $=800 \mu \mathrm{m})$.

Figure 3 shows the grains in the samples cast after the addition of master alloy. The grain size of the reference alloy is reduced with the addition of oxide-based master alloy. The grain size was found to be smaller with the additions of master alloy in the range from $0.25 \mathrm{wt} \%$ to $5.8 \mathrm{wt} \%$. However, the grain size refinement is most pronounced at $1.7 \mathrm{wt} \%$ addition, from $900 \mu \mathrm{m}$ to 400 $\mu \mathrm{m}$. Further master alloy addition was not helpful in aditonal grain refinement. In contrast, an increase in grain size to 500 and $450 \mu \mathrm{m}$ was observed at $4.2 \mathrm{wt} \%$ and $5.8 \mathrm{wt} \%$ additions, respectively.

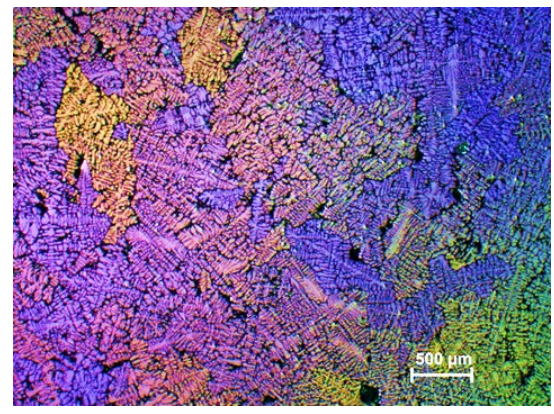

(a)

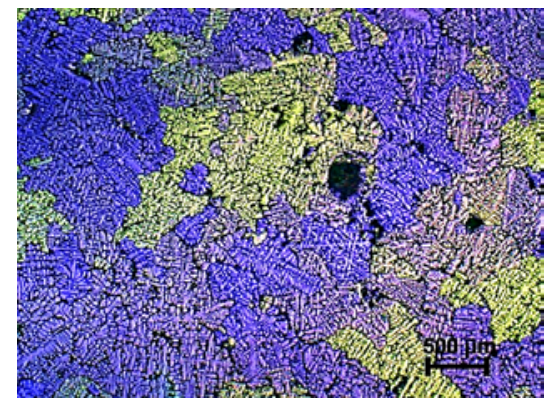

(d)

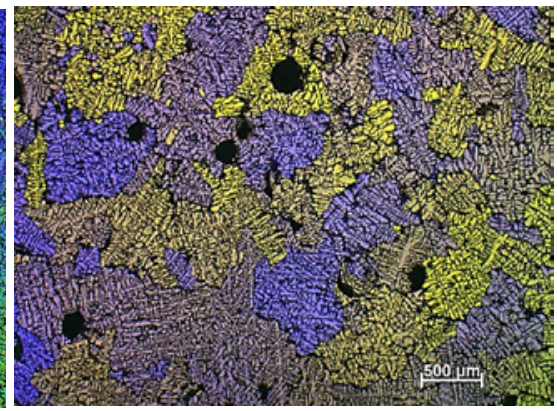

(b)

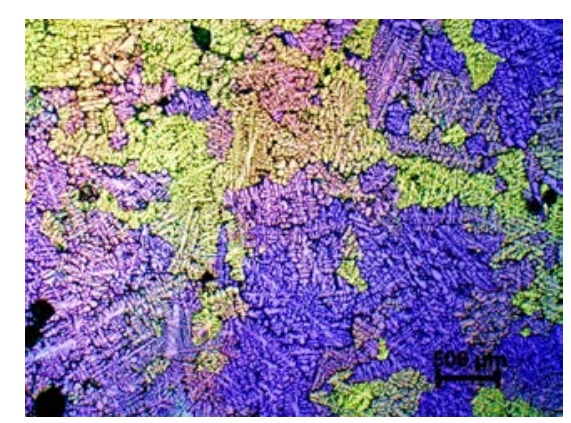

(e)

Fig. 3: Grain sizes in the A357 alloys cast with oxide-based master alloy additions (a) 0.25 wt\% (Avg G.S. = $740 \mu \mathrm{m})$, (b) $1 \mathrm{wt} \%(680 \mu \mathrm{m})$, (c) $1.7 \mathrm{wt} \%(400 \mu \mathrm{m})$, (d) $4.2 \mathrm{wt} \%(500 \mu \mathrm{m})$ and (e) 5.8 $\mathrm{wt} \%(450 \mu \mathrm{m})$.

Figure 4 demonstrates the grain structure the A357 alloy treated with ultrasound after the addition of master alloy. It can be easily seen that the grain sizes of the alloy were smaller as compared to the previous results. The average grain size of the alloy was reduced to $500 \mu \mathrm{m}$ at an addition of $0.25 \mathrm{wt} \%$ of the master alloy. The grain size further reached $370 \mu \mathrm{m}$ at an addition of $1.7 \mathrm{wt} \%$. After that, the addition was not seemed to be effective in further reduction of grain size. 


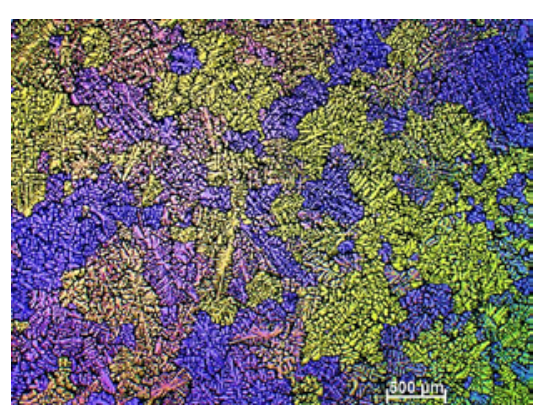

(a)

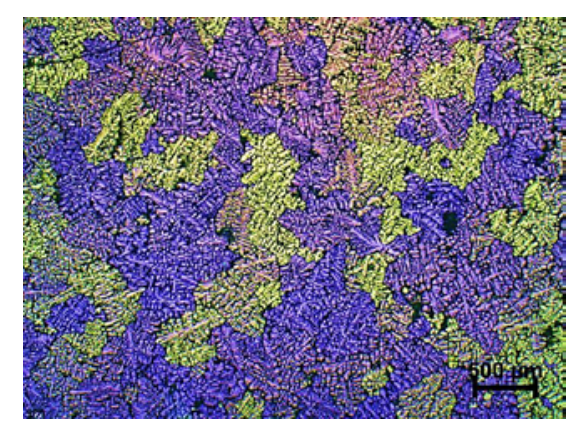

(d)

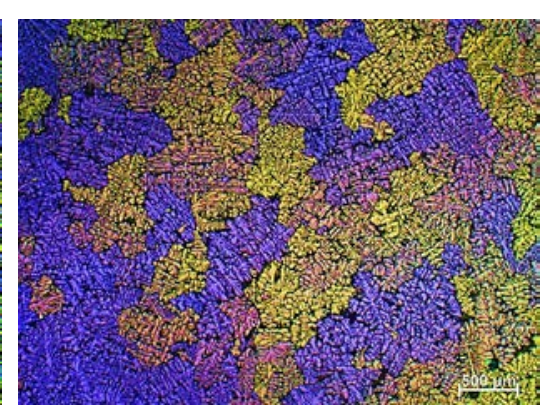

(b)

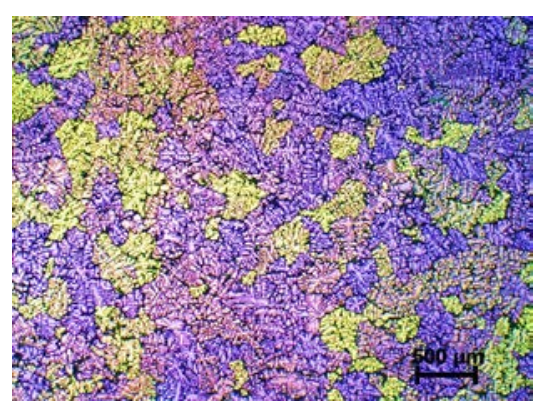

(c)

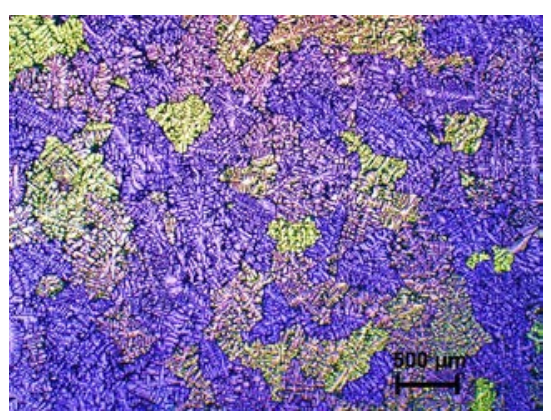

(e)

Fig. 4: Grain sizes of A357 alloys ultrasonicated after master alloy additions: (a) 0.25 wt\% (Avg G.S. $=500 \mu \mathrm{m})$, (b) $1 \mathrm{wt} \%(470 \mu \mathrm{m})$, (c) $1.7 \mathrm{wt} \%(370 \mu \mathrm{m})$, (d) $4.2 \mathrm{wt} \%(370 \mu \mathrm{m})$ and (e) $5.8 \mathrm{wt} \%$ (370 $\mu \mathrm{m})$.

Figures 5 and 6 give the grain size distribution from the centre to the edge of the cast sample with 1.7-wt\% master alloy. A clear variation in distribution of grain size was observed from centre to the edge of the sample in the alloy without ultrasonication. Elongated grains were evident at the edge. Large amount of pores or particle clusters were observed at the centre, which gradually diappear towards the sample surface. With the ultrasonication treatment, the grains were found to distribute more evenly from the centre to the edge of the sample (Fig. 6). Porosity or particle clusters were less evident in the centre and columnar grains were absent at the edge of the sample.

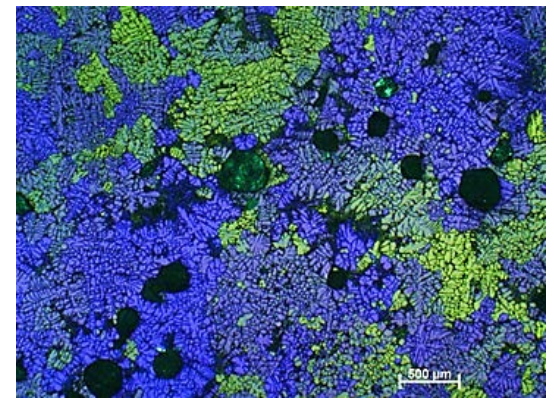

(a)

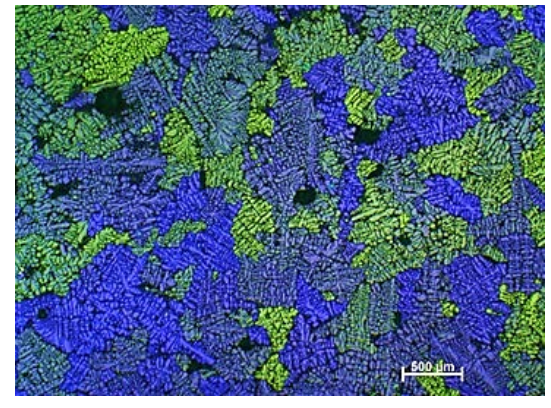

(b)

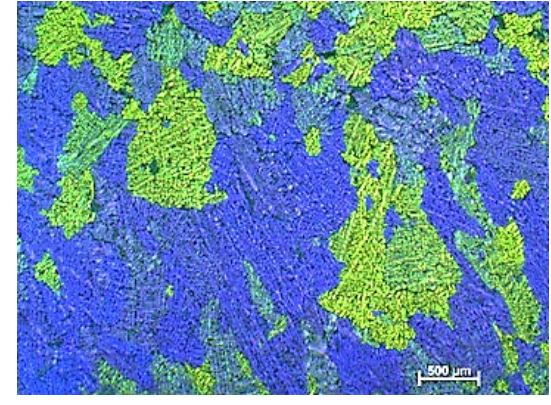

(c)

Fig. 5: Grain size distribution in an A357 alloy sample cast with $1.7 \mathrm{wt} \%$ master alloy addition at (a) centre of the sample (Avg G.S. $=550 \mu \mathrm{m})$, (b) middle portion of the sample $(400 \mu \mathrm{m})$ and (c) edge of the sample $(450 \mu \mathrm{m})$. 


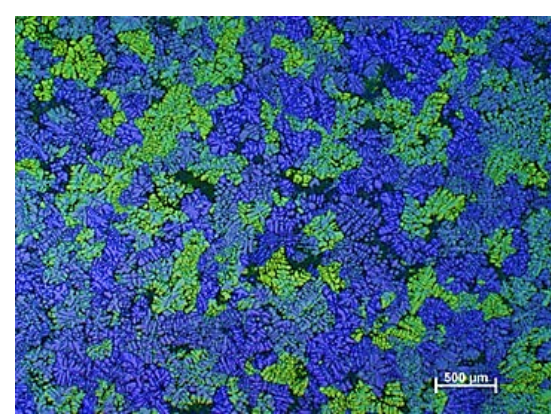

(a)

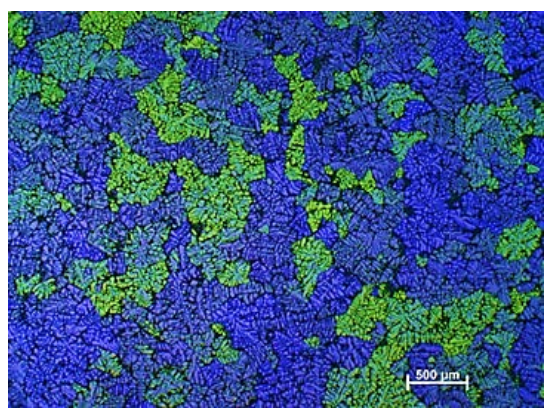

(b)

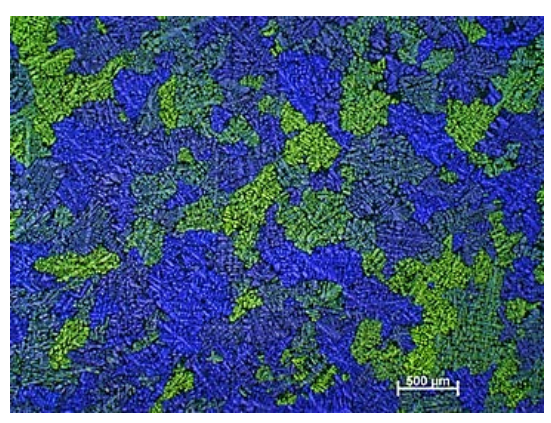

(c)

Fig. 6: Grain size distribution in and A357 alloy sample ultrasonicated after 1.7 wt\% master alloy addition at (a) centre of the sample (Avg G.S. $=350 \mu \mathrm{m}$ ), (b) middle portion of the sample (370 $\mu \mathrm{m})$ and (c) edge of the sample $(400 \mu \mathrm{m})$.

\section{Discussion}

The interfacial free energy at the nucleating interface is one of the controlling factors in heterogeneous nucleation. The importance of low interfacial energy for a potent substrate has been demonstrated long back by the classical nucleation theory [2]. However, the issues related to perfect wetting of exogenous inoculants with molten $\mathrm{Al}$ often fail to reduce the interfacial energy to lower level. Once particles are well wetted as often found in in-situ composites $\left(\mathrm{Al} / \mathrm{TiB}_{2}, \mathrm{Al} / \mathrm{MgAl}_{2} \mathrm{O}_{4}\right.$, $\mathrm{Al} / \mathrm{TiC})[8,9,13]$, nucleating potency can be related to the lattice matching at the solid/substrate interface during heterogeneous nucleation. The better the lattice matching, the higher the nucleation potency. In the present study, $\mathrm{MgAl}_{2} \mathrm{O}_{4}$ spinel was formed in-situ in molten Al. Crystallographic mismatch between $\mathrm{Al}$ and $\mathrm{MgAl}_{2} \mathrm{O}_{4}$ was estimated to be $1.41 \%$ along the [110] direction on the (111) plane [12]. It is clear that the lattice misfit between $\mathrm{MgAl}_{2} \mathrm{O}_{4}$ and $\mathrm{Al}$ is relatively small compared with that for the $\mathrm{Al} / \mathrm{TiB}_{2}$ system (-4.2\%), which satisfies the condition for a potent substrate [12]. Present investigation clearly demonstrates the grain refinement capability of $\mathrm{MgAl}_{2} \mathrm{O}_{4}$ spinel in the oxide-based master alloy.

Nucleation efficiency refers to the effectiveness of a given type of inoculant with specific physical characteristics and solidification conditions, such as number density, size, size distribution, and cooling rate. For a given nucleating system, nucleation potency is fixed but nucleation efficiency can be changed by modifying the physical characteristics of the nucleating particles and/or changing the solidification conditions [12]. For a given $\mathrm{MgAl}_{2} \mathrm{O}_{4}$ spinel crystal size (100-300 $\mathrm{nm}$ ) in the current study, amount of $\mathrm{MgAl}_{2} \mathrm{O}_{4}$ particles present in the master alloy seemed to be satisfying number density required for efficient grain refinement.

The difference in the grain refinement between ultrasonicated and non-ultrasonicated alloys can be correlated with the change in the number of the nucleating particles. Introduction of ultrasonic cavitation has a clear impact on the grain refinement in all the alloys studied. According to one of the theories of cavitation-aided grain refinement, cavitation can promote wetting of innoculant particles and turn them into additional solidification sites, which in turn leads to grain refinement $[14,15]$. Since wetting has been already established in the present scenario, cavitation and associated acoustic streaming may break the particle clusters and distribute throughout the metal. This increases the number of particles taking part for the nucleation event. There is a sharp change in grain size observed at 1.7 -wt\% addition of the master alloy, that may be due to more particles present in the alloy (Figs. 3 and 4). However, decrease in the grain size of non-ultrasonicated alloy with more additions (Fig. 3(d) and (e)) may be attributed to the clustering of spinel particles. In the case of ultrasonicated alloy, grain size seemed to remain the same at greater addition levels (Fig. 4(d) and (e)). Elimination of columnar grains (compare Fig. 5(c) and Fig. 6(c)) can be correlated to more particles available for heterogeneous nucleation after ultrasonication. The degassing by ultrasonication may also contribute to the disintegration of clusters associated with large porosities. 


\section{Summary}

(1) New oxide master alloy is capable of grain refining an A357 alloy.

(2) Introduction of ultrasonic cavitation along with master alloy addition improve the grain refinement of the alloy by $60 \%$.

(3) Addition levels of master alloy higher than $1.7 \mathrm{wt} \%$ do not show additional effect in grain size reduction.

\section{Acknowledgement}

The authors wish to acknowledge financial support from the ExoMet Project, which is co-funded by the European Commission in the 7th Framework Programme (contract FP7-NMP3-LA-2012280421), by the European Space Agency and by the individual partner organisations.

\section{References}

[1] D.G. McCartney, Grain Refining of Aluminium and Its Alloys Using Inoculants, Int. Mater. Rev., 34 (1989) 247-60.

[2] B.S. Murty, S.A. Kori, and M. Chakraborty, Grain refinement of aluminium and its alloys by heterogeneous nucleation and alloying, Int. Mater. Rev., 47 (2002) 3-29.

[3] K.T.Kashyap and T. Chandrasekhar, Effects and mechanisms of grain refinement in aluminium alloys, Bull. Mater. Sci., 24 ( 2001) 345-353.

[4] M. Easton and D. StJohn, Grain Refinement of Aluminum Alloys: Part I. The Nucleant and Solute paradigms. A Review of the Literature, Metall.Mater. Trans. A, 30A (1999) 1613-1623

[5] P.S.Mohanty, J.E. Gruzleski, Mechanism of grain refinement in aluminium, Acta Met. Mater., 43 (1995) 2001-2012

[6] P. Schumacher and A.L.Greer, Enhanced heterogeneously nucleated $\alpha$-Al in amorphous Aluminium alloys, Mater. Sci. Eng. A, 178 (1994) 309-313

[7] F. Wang , Z. Liu, D. Qiu, J. A. Taylor, M. A. Easton, M. X. Zhang, Revisiting the role of peritectics in grain refinement of Al alloys, Acta Mater., 61 (2013) 360-370

[8] Y. Birol, Production of Al-Ti-B master alloys from Ti sponge and $\mathrm{KBF}_{4}$, J. Alloys Comp., 440 (2007) 108-112

[9] V.H. Lopez, A. Scoles, A.R. Kennedy, The Thermal Stability of. TiC Particles in an Al7wt\%Si Alloy, Mater. Sci. Eng. A, 356 (2003) 316-325.

[10] A. L. Greer, Grain refinement of alloys by inoculation of melts, Phil. Trans. R. Soc. Lond. A, 361 (2003) 479-495

[14] G.I. Eskin, Ultrasonic Treatment of Light Alloy Melts, Gordon and Breach Science Publishers, Amsterdam, The Netherlands, 1998, pp. 18-60, 135-85, 229-40.

[11] T.V. Atamanenko, D.G. Eskin, L. Zhang, and L. Katgerman, Criteria of Grain Refinement Induced by Ultrasonic Melt Treatment of Aluminum Alloys Containing $\mathrm{Zr}$ and Ti, Metall. Mater. Trans. A, 41A (2010) 2056-2066

[12] H.-T. Li , Y. Wang, Z. Fan, Mechanisms of enhanced heterogeneous nucleation during solidification in binary Al-Mg alloys, Acta Mater., 60 (2012) 1528-1537 
[13] Y. Zhou, Z. Yu, N. Zhao, C., Shi, E. Liu, X. Du, C. He, Microstructure and properties of in situ generated $\mathrm{MgAl}_{2} \mathrm{O}_{4}$ spinel whisker reinforced aluminum matrix composites, Mater. Design, 46 (2013) 724-730

[15] O.V. Abramov, Ultrasound in Liquid and Solid Metals, CRC Press, Boca Raton, FL, 1994, pp. 43-77, 273-406. 